\title{
Editorials
}

\section{Mandatory reporting of female genital mutilation by healthcare professionals}

Female genital mutilation (FGM) is an abhorrent practice. FGM deliberately cuts the female genital organs for no medical reason and can have serious and long-lasting consequences including infertility, an increased risk of childbirth complications, a deleterious impact on maternal and infant mortality during and shortly after child birth, ${ }^{1}$ and significant psychological sequelae. The World Health Organization estimates that FGM affects about 100-140 million women and girls worldwide and each year it is estimated that an additional 3 million girls are at risk of being subjected to this practice.

It is believed that approximately 103000 women and girls aged 15-49 years and 24000 women aged $\geq 50$ years who have migrated to England and Wales are living with the consequences of FGM. Some 60000 girls aged $0-14$ years have been born in England and Wales to mothers who have undergone FGM and 10000 girls $<15$ years of age are likely to have undergone FGM. ${ }^{2}$

The Department of Health has published data from September to December 2014 that show 1946 newly-identified cases of FGM were reported nationally with 47 cases in women and girls aged $<18$ years. Currently, all clinicians (including GPs) are required to record in their clinical notes when a patient with FGM is identified, what type it is, and submit these data to the FGM national data collection. ${ }^{3}$

However, despite its relatively high prevalence and FGM being a serious crime, no successful prosecution has taken place since 1983, although a dentist was struck off the Dental Register in 2013 for offering to perform FGM. Why have so few cases been prosecuted? The police claim it is because very few cases are referred to them. ${ }^{4}$ GPs, in turn, claim that FGM can be a difficult condition to identify and discuss with patients (particularly in adults) and there is an overwhelming need to protect confidentiality and avoid damaging the doctor-patient relationship. In addition, some doctors are concerned that they may lack the necessary knowledge and skills to manage the condition. ${ }^{5}$

To address these issues, the UK government has recently proposed mandatory reporting of visualised or disclosed' FGM by GPs direct to the police. The recent acquittal of a doctor accused of FGM following delivery of a child ${ }^{6}$ has

despite its relatively high prevalence and FGM being a serious crime, no successful prosecution has taken place.

emphasised the difficulty of not only identifying what actually constitutes the crime of FGM but also the complexity of the arrangements for the mandatory reporting of FGM.

A consultation paper on the introduction of mandatory reporting for FGM was published in December 2014. ${ }^{7}$ Its purpose was to enable the UK government to scope and fully explore how a mandatory reporting requirement for cases of FGM could be introduced. This consultation has now closed and the government has decided to press ahead with a new mandatory reporting duty on GPs for FGM through amendments to the Serious Crime Act.

\section{'KNOWN' CASES OF FGM}

The proposed new duty on GPs will apply in cases of 'known' FGM (that is, instances disclosed by the victim and/or visually confirmed). The position related to 'suspected' and 'at risk' cases will remain the same and professionals will be expected to refer cases appropriately as set out in the Multi-Agency Practice Guidelines on FGM using the existing safeguarding framework and procedures. $^{8}$ The government's initial proposal was to include all women within the provision for mandatory reporting. However, following intense lobbying this provision has now been withdrawn and the new duty will apply to young women and girls $<18$ years of age.

The new duty will also be extended to include not only all regulated social and healthcare professionals but also teachers. Fortunately, the new duty will not mean that there is a new requirement for professionals to look for visual evidence of FGM and reporting will be confined to cases that are encountered during the course of their 'usual' professional duties.

One of the difficulties with mandatory reporting of FGM is that although such legislative reporting duties exist in a wide range of countries across the world, there is an absence of both evidence and data that mandatory reporting better protects children: nor does it tackle the issue of the under-reporting of concerns. ${ }^{9}$ There are already many duties on us as GPs under the existing child protection procedures and although mandatory reporting of FGM may be well-intentioned, it will almost certainly have additional unintended consequences.

Such unintended consequences may include a reluctance by families to seek advice for pregnancy and childbirth, seek help for the early/late consequences of FGM, destroy the confidentiality of the consultation, and damage the important long-term doctor-patient relationship. In addition, there are currently very few resources available within most health economies (for example, de-infibulation clinics) to which doctors can refer women or young girls who have experienced FGM.

Mandatory reporting of cases of 'visualised' FGM should not, therefore, be made directly to the police rather than the local safeguarding board under the current Multi-Agency Practice Guidelines. ${ }^{8}$ FGM is a severe form of child abuse and there is no good rationale for treating it in a different way from other forms of child abuse, where the child is referred to social services with the police becoming involved at a later date. Indeed, it is difficult to see what purpose mandatory reporting direct to 


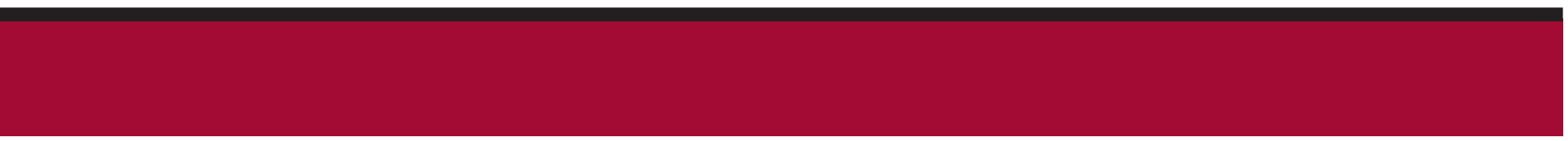

\section{a mandatory referral duty on GPs direct to the police of 'visualised' FGM will [not] address the problem ...}

the police serves, given that child abuse is not generally dealt with by the police in the initial stages of the investigation.

The government's proposal that failure to comply with the new duty will be dealt with via existing disciplinary frameworks Irather than their initial proposal which was to report doctors to the Disclosure and Barring Servicel is to be welcomed; since the majority of cases of failure to report FGM are likely to be the result of a lack of understanding or knowledge of FGM by the clinician. Visual confirmation of FGM, particularly types 1 and 4, is not always straightforward and not all GPs will be sufficiently expert in this area to make a definitive diagnosis. It would be particularly helpful for GPs to be able to report a suspected case of FGM to other agencies who may be able to visually confirm a case more easily without the need to inform either the police or social care.

\section{SECONDARY CARE}

Mandatory reporting also applies to doctors in secondary care and all acute hospitals must submit monthly statistics on women who had been found to have had FGM and those aged $<18$ years must be reported under the Serious Crime Bill. The introduction of mandatory reporting aims to break down the professional barriers regarding confidentiality and cultural sensitivity and will hopefully send out a message to the perpetrators that they will be prosecuted. Each hospital now has a designated person responsible for the collecting of FGM cases and reporting them. By recording these data, NHS commissioners can decide where to provide dedicated FGM services.

Closer working between GPs and secondary care is vital so that women who have been identified are followed in their journey and their children protected. GPs unfamiliar with FGM should refer to specialist clinics for verification of FGM type, reversal if indicated, and support.

The recent case of an obstetrics and gynaecology specialist trainee claiming to be ignorant of $\mathrm{FGM}^{6}$ demonstrates that we need to do more with regards to educating doctors in training. With the recent media focus on
FGM, and events such as the Girl Summit 2014, where heads of state, practitioners, survivors, charities, and community groups assembled to secure new commitments on FGM and child and early and forced marriage (CEFM), ignorance of FGM is no longer an excuse. However we should ensure that FGM is in the undergraduate curriculum of all UK medical schools and online training (for example, e-learning programmes) should be a compulsory 'sign off' for foundation doctors, and also in specialty training programmes, particularly paediatrics, obstetrics and gynaecology, emergency medicine, and general practice.

\section{CONCLUSION}

Clearly, as physicians and citizens, we should obey the law, and as a society we do need to do more to address the issue of FGM and refer any girls whom we feel may be at risk.

We already have a statutory obligation to refer cases of child abuse and neglect to the local safeguarding board on which the police already sit. In our view, the case has not yet been made that a mandatory referral duty on GPs direct to the police of 'visualised' FGM will address the problem of lack of identification, it will not simplify referral pathways, and nor will it play an important role in deterring perpetrators and prevent this appalling crime taking place.

In our role as healthcare professionals, we can be individual practitioners and key agents of social change by working with individual women and their families to prevent FGM. However, real change in the prevalence and practice of FGM must come from within the communities themselves.

\section{Nigel Mathers,}

Professor of Primary Medical Care, The University of Sheffield and Honorary Secretary of the Royal College of General Practitioners.

\section{Janice Rymer,}

Professor of Gynaecology, King's College London School of Medicine, London.

\section{Provenance}

Commissioned; not externally peer reviewed.

DOI: 10.3399/bjgp15X685141

\section{ADDRESS FOR CORRESPONDENCE}

\section{Nigel Mathers}

Academic Unit of Primary Medical Care, The University of Sheffield, Northern General Hospital, Herries Road, Sheffield, S5 7AU, UK.

\section{E-mail: n.mathersðsheffield.ac.uk}

\section{REFERENCES}

1. World Health Organisation. Female Genital Mutilation. Fact sheet No241. unw.who.int/ mediacentre/factsheets/fs241/en/ laccessed 6 May 2015).

2. Macfarlane A, Dorkenoo E. Female genital mutilation in England and Wales: updated statistical estimates of the numbers of affected women living in England and Wales and girls at risk. Interim report on provisional estimates. http://www.equalitynow.org/sites/default/ files/FGM\%20EN\%20City\%20Estimates.pdf laccessed 6 May 2015).

3. Health and Social Care Information Centre. FGM enhanced dataset implementation summary for GP practices. http://www.hscic. gov.uk/media/16755/FGM-Enhanced-DatasetImplementation-Summary-for-GP-Practices/ pdf/FGM_Enhanced_Dataset_Implementation_ Guidance_Summary_for_GPS_FINAL.pdf laccessed 6 May 2015).

4. Home Affairs Select Committee on Female Genital Mutilation. Female genital mutilation. http://unw.parliament.uk/business/ committees/committees-a-z/commonsselect/home-affairs-committee/inquiries/ parliament-2010/female-genital-mutilation/ (accessed 6 May 2015).

5. Royal College of General Practitioners. Home Affairs Select Committee Inquiry into female genital mutilation: written evidence from the Royal College of General Practitioners. http:// unw.rcgp.org.uk/policy/rcgp-policy-areas/ / media/Files/Policy/A-Z-policy/FGM-inquiryRCGP-Written-Evidence.ashx laccessed 7 May 2015).

6. BBC News. Doctor found not guilty of performing FGM. http://unw.bbc.co.uk/news/ uk-england-31138218 (accessed 6 May 2015).

7. Home Office. Introducing mandatory reporting for female genital mutilation consultation - summary of responses. https://uww.gov. uk/government/uploads/system/uploads/ attachment_data/file/403436/Government response_to_the_Consultation_on_the_ Mandatory_Reporting_of_FGM.pdf laccessed 6 May 2015).

8. HM Government. Multi-agency practice guidelines - female genital mutilation. https://www.gov.uk/government/uploads/ system/uploads/attachment_data/file/380125/ MultiAgencyPracticeGuidelinesNov14.pdf laccessed 6 May 2015).

9. Royal College of Paediatrics and Child Health. Home Office consultation - Introducing mandatory reporting for female genital mutilation. Consultation response submitted by the Royal College of Paediatrics and Child Health. http://www.rcpch.ac.uk/system/files/ protected/consultation/RCPCH\%20Final\%2O Response\%20Jan\%202015.pdf laccessed 6 May 2015). 